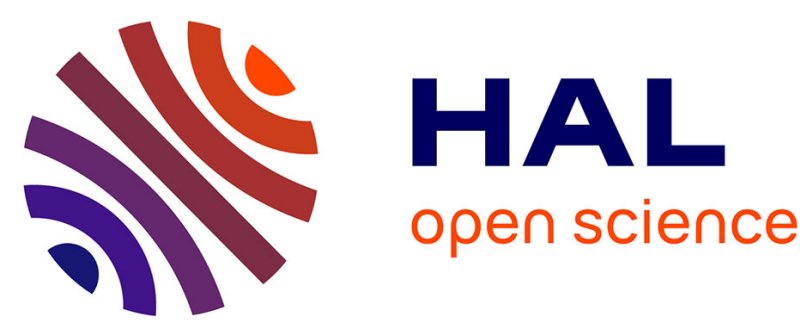

\title{
Numerical modeling of the mount Steller landslide flow history and of the generated long period seismic waves
}

Laurent Moretti, Anne Mangeney, Yann Capdeville, Eléonore Stutzmann, Christian Huggel, Demian Schneider, François Bouchut

\section{- To cite this version:}

Laurent Moretti, Anne Mangeney, Yann Capdeville, Eléonore Stutzmann, Christian Huggel, et al.. Numerical modeling of the mount Steller landslide flow history and of the generated long period seismic waves. Geophysical Research Letters, 2012, 39 (16), pp.L16402. 10.1029/2012GL052511. hal-00728958

\section{HAL Id: hal-00728958 \\ https://hal.science/hal-00728958}

Submitted on 3 Nov 2017

HAL is a multi-disciplinary open access archive for the deposit and dissemination of scientific research documents, whether they are published or not. The documents may come from teaching and research institutions in France or abroad, or from public or private research centers.
L'archive ouverte pluridisciplinaire HAL, est destinée au dépôt et à la diffusion de documents scientifiques de niveau recherche, publiés ou non, émanant des établissements d'enseignement et de recherche français ou étrangers, des laboratoires publics ou privés. 


\title{
Numerical modeling of the Mount Steller landslide flow history and of the generated long period seismic waves
}

\author{
L. Moretti, ${ }^{1,2}$ A. Mangeney, ${ }^{1,2}$ Y. Capdeville, ${ }^{1,3}$ E. Stutzmann, ${ }^{1}$ C. Huggel, ${ }^{4}$ D. Schneider, ${ }^{4}$ \\ and F. Bouchut ${ }^{5}$
}

Received 29 May 2012; revised 18 July 2012; accepted 21 July 2012; published 28 August 2012.

[1] The rock-ice avalanche that occurred in 2005 on Mount Steller, Alaska and the resulting long period seismic waves have been simulated for different avalanche scenarios (i.e., flow histories), with and without erosion processes taken into account. This $40-60 \mathrm{Mm}^{3}$ avalanche traveled about $10 \mathrm{~km}$ down the slope, mainly on top of a glacier, eroding a significant amount of ice. It was recorded by 7 broadband seismic stations. The simulations were compared with the recorded long period seismic signal and with the inverted flow history. The results show that, when erosion processes are taken into account, the simulations reproduce the observed signal at all the stations over a wide range of azimuths and source-station distances $(37-623 \mathrm{~km})$. This comparison makes it possible to constrain the rheological parameters involved which should help constrain the volume of eroded material. Because landslides are continuously recorded by seismic networks, this method could significantly broaden quantitative insights into natural flow dynamics. Citation: Moretti, L., A. Mangeney, Y. Capdeville, E. Stutzmann, C. Huggel, D. Schneider, and F. Bouchut (2012), Numerical modeling of the Mount Steller landslide flow history and of the generated long period seismic waves, Geophys. Res. Lett., 39, L16402, doi:10.1029/2012GL052511.

\section{Introduction}

[2] Landslides and avalanches are key erosion processes and major natural hazards. Despite important research efforts, the mechanisms that govern flow dynamics and deposition in a natural environment are still unclear and key questions remain unanswered, such as the origin of the high mobility of some natural flows [e.g., Legros, 2002; Mangeney-Castelnau et al., 2005; Lucas and Mangeney, 2007; Pudasaini and Hutter, 2007; Iverson et al., 2011]. There are two reasons for this. First, most numerical models do not take into account the complex physical processes

\footnotetext{
${ }^{1}$ Équipe de Sismologie, Institut de Physique du Globe de Paris, UMR 7154, PRES Sorbonne Paris Cité, Paris, France.

${ }^{2}$ UFR STEP, Université Paris-Diderot 7, Paris, France.

${ }^{3}$ Laboratoire de Planétologie et Géodynamique de Nantes, Nantes, France.

${ }^{4}$ Glaciology, Geomorphodynamics and Geochronology, Department of Geography, University of Zurich, Zurich, Switzerland.

${ }^{5}$ LAMA-UMR 8050, Université Paris-Est-Marne-la-Vallée, Paris, France.

Corresponding author: L. Moretti, Équipe de Sismologie, Institut de Physique du Globe de Paris, UMR 7154, PRES Sorbonne Paris Cité, Paris FR-75005, France. (1moretti@ipgp.fr)

C2012. American Geophysical Union. All Rights Reserved. 0094-8276/12/2012GL052511
}

such as erosion/deposition or fluid/solid interaction. Second, field measurements relevant to landslide dynamics are scarce, making it difficult to validate models.

[3] Recent studies have shown that long-period seismic signals generated by landslides and continuously recorded by seismic networks can be analyzed to provide a unique diagnostic of these flows. They therefore provide a way to validate flow models and improve the understanding of the physical processes at work. Indeed, the stress applied by the landslide to the bed surface, which generates the seismic waves, is highly sensitive to the flow dynamics during mass emplacement [Brodsky et al., 2003; Favreau et al., 2010; Schneider et al., 2010].

[4] Single-force source models have been proposed to analyze low frequency seismic records, essentially derived from the simple scheme of a block sliding over a slope [Kanamori and Given, 1982; Kawakatsu, 1989; Brodsky et al., 2003; Lin et al., 2010]. This can be used to estimate the landslide volume and the mean rheological parameters (friction). Detailed landslide simulations over 3D topography have also been performed and the simulated energy, momentum, frictional work rate and acceleration have been qualitatively compared to the observed seismic signal [Ward and Day, 2006; Schneider et al., 2010]. In a first attempt to couple the detailed simulation of landslide dynamics and the generated seismic waves, Favreau et al. [2010] showed that comparison of simulated and recorded seismic signals can be used to discriminate different flow scenarios and estimate the rheological parameters involved. However, the feasibility of this method was only demonstrated for one landslide recorded by only two seismic stations, tens of $\mathrm{km}$ from the source.

[5] Here we apply this method to the $40-60 \mathrm{Mm}^{3}$ Mount Steller rock-ice avalanche recorded by 7 broadband seismic stations covering a wide range of azimuths and distances $(37-623 \mathrm{~km})$. As opposed to the Thurwieser landslide, this avalanche moved a significant amount of material eroded from the underlying glacier. Comparing long-period simulated and recorded seismic signals would help to get first estimates of the eroded volume and to investigate erosion effects on avalanche dynamics. When erosion was taken into account, very good agreement was obtained between simulated and observed seismic signals for all the stations.

\section{Observed Avalanche and Seismic Signal}

[6] On September 14th 2005 ( $\simeq 19$ h59 UT), the summit area of the southern flank of Mount Steller (N60.52, W143.09), Chugach Mountains, Alaska, collapsed and the resulting $40-60 \mathrm{Mm}^{3}$ avalanche traveled about $10 \mathrm{~km}$, mainly over a glacier, before finally stopping (Figures 1a 

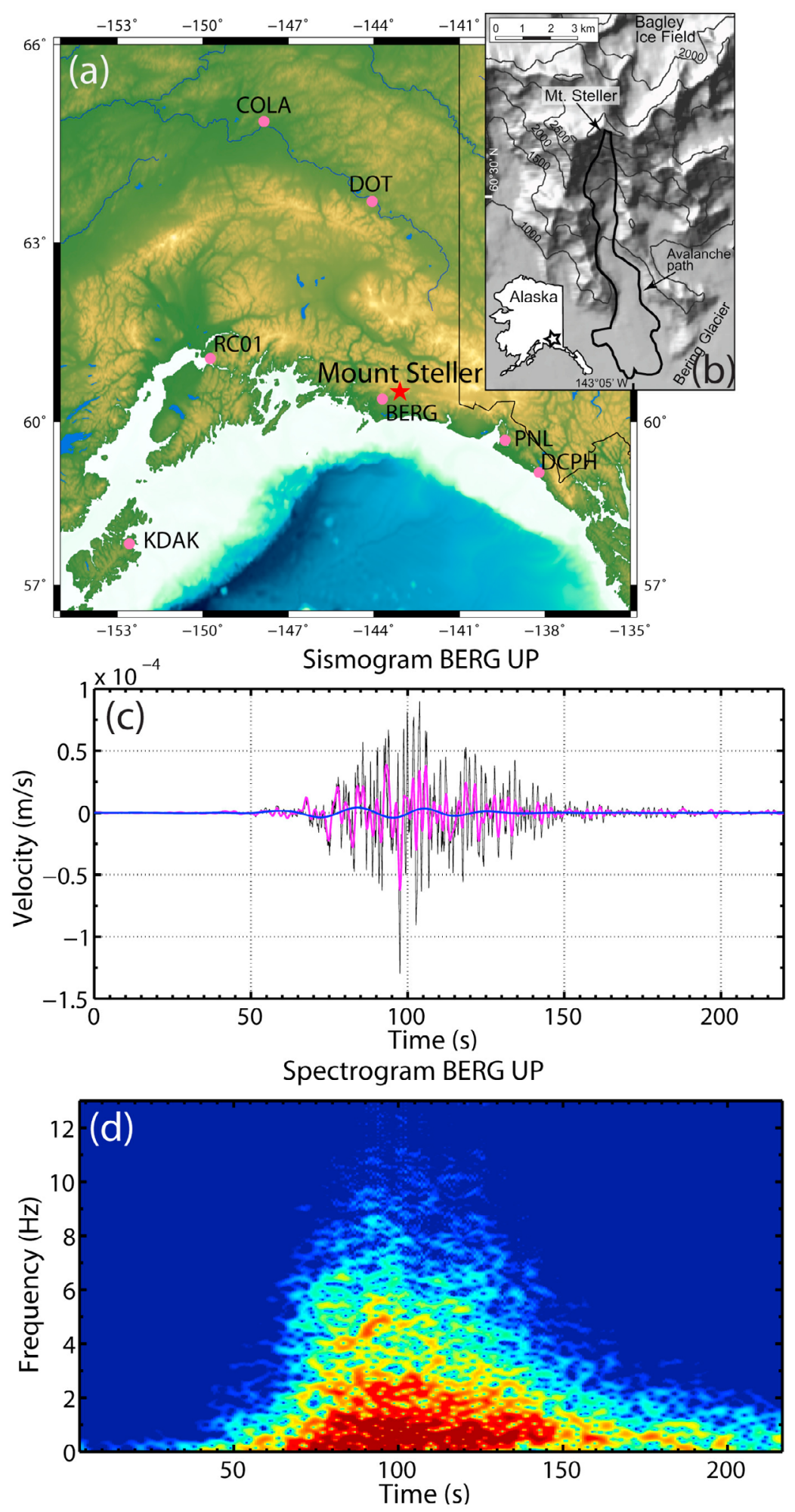

Figure 1. (a) Location of Mount Steller, the seismic stations (pink dots) and the avalanche (red star). (b) Mount Steller map and avalanche path. (c) Raw (black), filtered 2-20 s (pink) and filtered 20-80 s (blue) vertical ground velocity as a function of time. (d) Associated spectrogram recorded at BERG station.

and $1 \mathrm{~b}$ ). Field surveys have shown that the flowing mass was composed of (i) the initial collapsing rock-ice mass estimated to be made up of $3-4.5 \mathrm{Mm}^{3}$ of ice, $2 \mathrm{Mm}^{3}$ of snow and $10-20 \mathrm{Mm}^{3}$ of rock [Huggel et al., 2008] and (ii) material eroded from the glacier along the avalanche path. The only available constraint on the deposit is its area, with an uncertainty of maximum $5 \%$ on the runout distance (Figure 1b). 
[7] The seismic signal generated by the avalanche was recorded by 7 broadband seismic stations covering a wide range of azimuths and source-station distances $(37-623 \mathrm{~km})$ (Figure 1a). Figures 1c and 1d show the typical emergent onset of landslide generated seismic signals; the signal lasts about $130 \mathrm{~s}$ at BERG station. At all the stations, the spectrogram has a characteristic cigar shape with a frequency content $f \in[0.004,1.5] \mathrm{Hz}$, similar to the seismic signal generated by the Thurwieser landslide [Favreau et al., 2010].

\section{Landslide Simulation}

[8] We used the SHALTOP numerical model to compute the spatio-temporal stress field applied by the flow to the ground surface at the origin of the seismic waves. This model describes homogeneous continuous granular flows over a 3D topography [Bouchut et al., 2003; Bouchut and Westdickenberg, 2004; Mangeney-Castelnau et al., 2005; Mangeney et al., 2007b]. It is based on the depth-averaged thin layer approximation. It calculates the flow thickness $h(\mathbf{x}, t)$ in the direction normal to the topography $z=b(x, y)$ and the two-dimensional depth-averaged flow velocity $\mathbf{u}(\mathbf{x}, t)$ of the granular media, where $(x, y, z)$ are the horizontal/ vertical coordinates and $\mathbf{x}=(x, y)$.

[9] Using Coulomb type friction laws, SHALTOP has been used to successfully reproduce experimental granular flows as well as natural landslides [Kuo et al., 2009; Lucas et al., 2011; Favreau et al., 2010; Hibert et al., 2011]. In depth-averaged models, the empirical friction coefficient essentially represents the mean energy dissipation during the flow.

[10] Erosion processes are hard to describe in depth-averaged models [Bouchut et al., 2008]. Farin et al. [2011] showed that the runout distance of granular flows over thin erodible beds can be roughly reproduced using the so-called Pouliquen and Forterre flow law. This law involves a variable friction coefficient $\mu$ that depends on the so-called inertial number $I=\|\mathbf{u}\| /(h \sqrt{g h})$ representing the ratio between the shear stress and the square root of the pressure, where $g$ is the gravity acceleration [Pouliquen and Forterre, 2002; Jop et al., 2006]. Granular flow experiments show that the friction angle $\delta$ during the flow essentially varies in between two empirical values $\delta_{1}$ and $\delta_{2}$ through the relation

$$
\mu(I)=\tan \delta(I)=\tan \delta_{1}+\left(\tan \delta_{2}-\tan \delta_{1}\right) \frac{1}{\frac{1}{I}+1}
$$

where $I_{0}=0.45$ is an empirical constant. This flow law takes also into account a starting friction angle (for very small Froude numbers) following a relation similar to equation (1) but with empirical friction coefficients $\delta_{3}$ and $\delta_{4}$ a few degrees higher than $\delta_{1}$ and $\delta_{2}$, respectively (see Mangeney et al. [2007b, equations (13)-(15)] for more details). The main feature of this flow law is that the friction coefficient increases when the flow thickness decreases and the Froude number increases. Erosion is very simply described here by the fact that the material layer at rest on the slope can be moved by the flow that passes over it.

[11] To estimate the role of erosion in the flow dynamics, two scenarios were investigated: (1) without erosion where the whole mass of $57 \mathrm{Mm}^{3}$ was released on top of Mount Steller (Figure 2a) and (2) with erosion where only $47 \%$ of the mass, i.e. $27 \mathrm{Mm}^{3}$, was released at the summit and the remaining $30 \mathrm{Mm}^{3}$ of material lay initially at rest on the glacier (Figure 2d). The shape of the released mass was simply assumed to be parabolic.

[12] As usual, the friction angles were calibrated to reproduce the observed runout distance which is known to be a robust constrain [e.g., Kuo et al., 2009; Schneider et al., 2010, Lucas et al., 2011]. The presence of the glacier was taken into account simply by reducing the friction coefficient when the flow passed over it [Favreau et al., 2010]. As roughly observed experimentally, the friction angles have been chosen to be $\delta_{2}=\delta_{1}+10^{\circ}, \delta_{3}=\delta_{1}+2^{\circ}$ and $\delta_{4}=\delta_{1}+$ $2^{\circ}$, so that the two control parameters are $\delta_{g 1}$ on the glacier and $\delta_{r 1}$ elsewhere. On the glacier, covering $80 \%$ of the avalanche path, $\delta_{g 1}=7^{\circ}$ for the two scenarios whereas, on the bedrock, $\delta_{r 1}=18^{\circ}$ for scenario 1 and $\delta_{r 1}=11^{\circ}$ for scenario 2 . The flow dynamics and runout distance are mainly controlled by the friction angle on the glacier: decreasing $\delta_{g 1}$ by $3^{\circ}$ increases the runout by more than $35 \%$ while the same decrease of $\delta_{r 1}$ increases the runout by only $5 \%$. Here the error of $5 \%$ on the runout measurement results in an error of about $1^{\circ}$ on $\delta_{g 1}$. For both scenarios, the simulated flow duration $(\simeq 130 \mathrm{~s})$, runout distance and area of the deposit were very similar and compare well with the observations (Figures $2 \mathrm{~g}$ and $2 \mathrm{~h}$ ). The mass distribution within the deposit however differs significantly in the two scenarios. In scenario 1 (without erosion), the main part of the mass was deposited upslope whereas in scenario 2 (with erosion), the thickest deposit is located downslope, near the mass front. This could be related to the development of steep fronts observed in granular flows over erodible beds [Pouliquen and Forterre, 2002; Mangeney et al., 2007a, 2010]. Indeed, the flowing mass front was gentle for scenario 1 (Figure 2b) while it resembled a surge wave for scenario 2 (Figure 2e). Because there were no precise field constraints on the mass distribution of the deposit, we used here the generated seismic signal to discriminate between the two scenarios. Indeed, Favreau et al. [2010] showed that, fitting the flow to reproduce the generated seismic signals, makes it possible to recover the morphology of the Thurwieser landslide deposits, for which precise measurements were available.

\section{Flow History and Seismic Wave Modeling}

[13] The source function, i.e. the spatio-temporal basal stress field, can be directly deduced from the landslide simulations. In order to strictly preserve the force balance between the initial and final states, third order terms in the thin layer asymptotic development have to be included in the calculation of the three-dimensional stress field $\mathbf{T}(\mathbf{x}, t)$ by surface unit $d \mathbf{x} / c$ (Favreau et al. [2010] only used first order terms)

$$
\mathbf{T}=-P_{\text {bottom }} \vec{n}+\rho \mu \frac{\left(g h c\left(\mathrm{I} d-\frac{h}{2} \operatorname{cof}\left(\partial_{\mathbf{x}} \mathbf{s}\right)^{t}\right) c \mathbf{u}\right)^{\operatorname{tg}}}{\left\|(c \mathbf{u})^{t g}\right\|}\left(1+\frac{\mathbf{u}^{t} \mathcal{H} \mathbf{u}}{g c}\right)_{+},
$$

where $\vec{n}=(-\mathbf{s}, c)$ is the unit vector normal to the topography, $\mathrm{c}=\cos \theta$, with $\theta$ the steepest slope angle, $\mathbf{s}=c \nabla_{\mathbf{x}} b, \rho$ is the density of the flowing mass, $\mathbf{I} d$ is the identity matrix, cof is the matrix of cofactors of a given matrix, and $(\mathbf{V})^{t g} \equiv\left(\mathbf{V}, \mathbf{s}^{t} \mathbf{V} / c\right)$, with $\mathbf{V}$ a given vector. The index + stands for the positive part, $x_{+}=\max (0, x)$. Note that $(c \mathbf{u})^{t g}$ is the three-dimensional velocity vector, tangent to the topography, 
Time : 0 secs

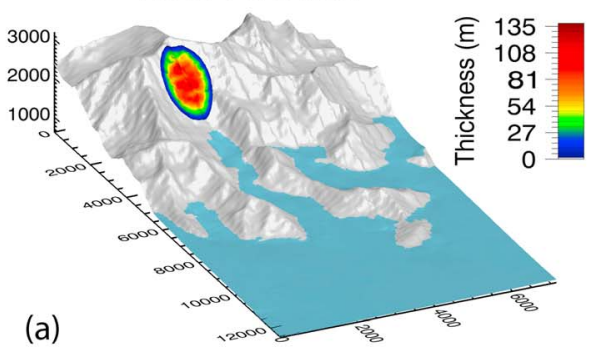

Time : 68 secs.

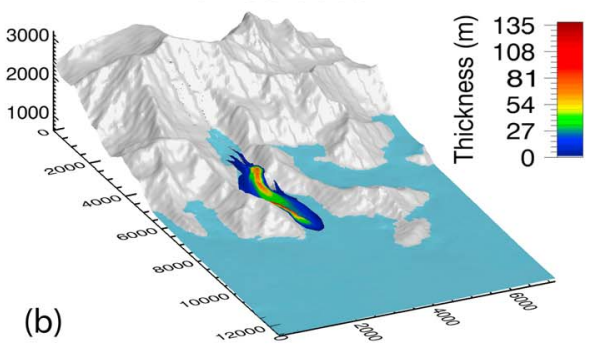

Time : 170 secs.

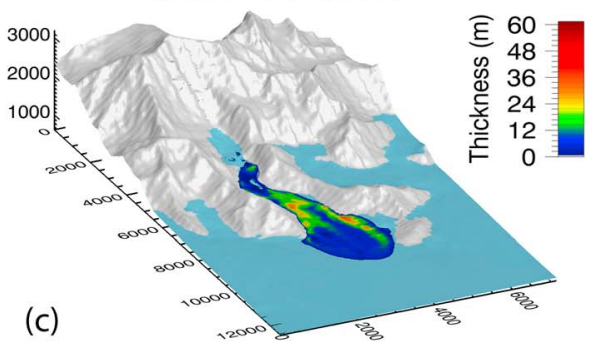

Time : 0 secs.

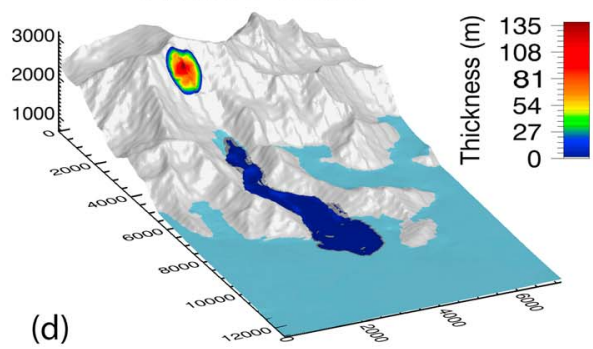

Time : 68 secs.

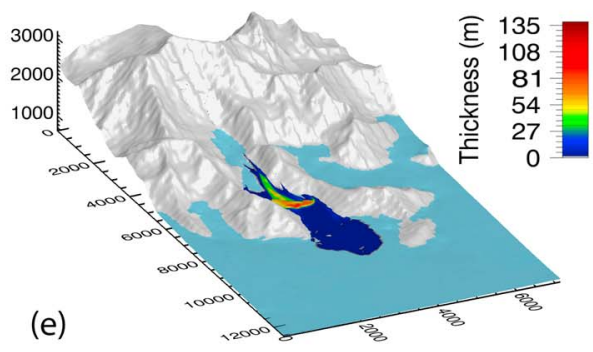

Time : 170 secs.

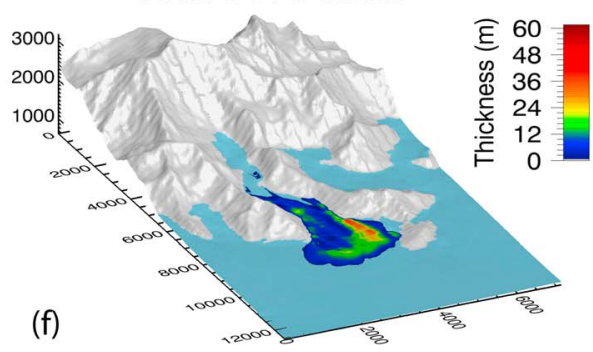

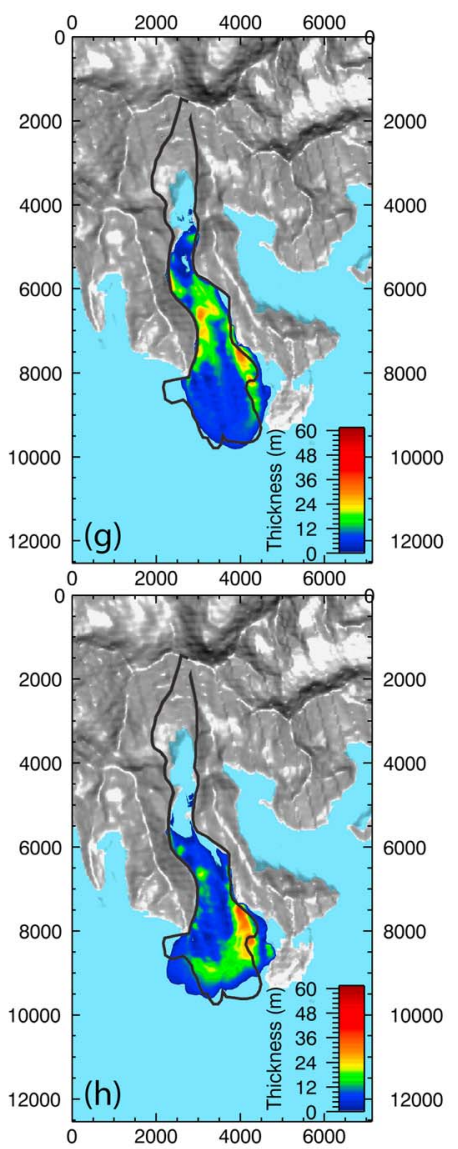

Figure 2. Numerical modeling of the Mount Steller ice-rock avalanche using the SHALTOP model for (a-c) scenario 1 (without taking erosion into account) and $(\mathrm{d}-\mathrm{f})$ scenario 2 (with erosion). $(\mathrm{g}, \mathrm{h})$ The deposits corresponding to Figures $2 \mathrm{c}$ and $2 \mathrm{f}$, respectively. Figures $2 \mathrm{a}$ and $2 \mathrm{~d}$ show initial states, and Figures $2 \mathrm{~b}$ and $2 \mathrm{e}$ represent flowing mass at $\mathrm{t}=68 \mathrm{~s}$. The black line in Figures $2 \mathrm{~g}$ and $2 \mathrm{~h}$ is the contour of the avalanche path. The glacier is represented in cyan.

and $\mathcal{H}=c^{3} \partial_{\mathbf{x x}}^{2} b$ is the curvature matrix of the topography. The pressure at the bottom $P_{\text {bottom }}$ is expressed as

$$
P_{\text {bottom }}=\rho g c h+\rho h \mathbf{u}^{t} \mathcal{H} \mathbf{u}+\frac{\rho c^{2} h^{2}}{2}\left(\operatorname{tr}\left(\left(\partial_{\mathbf{x}} \mathbf{u}\right)^{2}\right)+\left(\nabla_{\mathbf{x}} \cdot \mathbf{u}\right)^{2}\right),
$$

where $t r$ denotes the trace of a matrix.

[14] There are two ways to compare numerical modeling and seismic data: (i) compare the simulated force history to the source force inverted from seismic data (Figures 3a-3c), (ii) simulate the seismic waves generated by the modeled stress history and compare them to the recorded seismic signal (Figure 3d).

[15] To do that, we computed Green's function by solving the elastodynamic equations in a horizontally stratified half space without topography, using the discrete wavenumber method [Bouchon, 1981; Favreau et al., 2010] and an earth model composed of the crust2.0 [Bassin et al., 2000] at the Mount Steller location for the upper part and the PREM model below [Dziewonski and Anderson, 1981]. Green's functions were used either to (i) deconvolute the 3 components of the seismic signal recorded at the 7 stations to perform the inversion for the source function or (ii) convolute the modeled source function to simulate the generated seismic waves.
[16] Because continuum approach does not describe high frequencies generated by rock collisions, only long periods were considered here $(20 \mathrm{~s}<T<80 \mathrm{~s}$, i.e., $160 \mathrm{~km} \geq \lambda \geq$ $40 \mathrm{~km}$ ), for which wave propagation was expected to be weakly affected by the topography. Using the extended stress field or its spatial integral applied at a point source located on top of Mount Steller gives almost the same simulated seismic signal for the considered period range and source-station distances.

[17] The resulting 3 components of the space-averaged point force (stress multiplied by the covered area), called the source function, is represented in Figures $3 a-3 c$ for the two scenarios together with the force inverted from seismic data. Beside global acceleration and deceleration phases, simulation and observation show the complexity of the flow history related to the interplay between topography effects and landslide behavior. Scenario 2 (with erosion) better reproduces the vertical component of the inverted force, in particular the maximum downward peak and following upward force. This is less clear for the horizontal components.

[18] Note that in depth-averaged models, the initial mass release is poorly described, first because nucleation processes occurring at the beginning of the landslides are not taken into account, and also because of the intrinsic approximations that result in an infinite acceleration over the very first time step [Mangeney et al., 2010]. Because this 

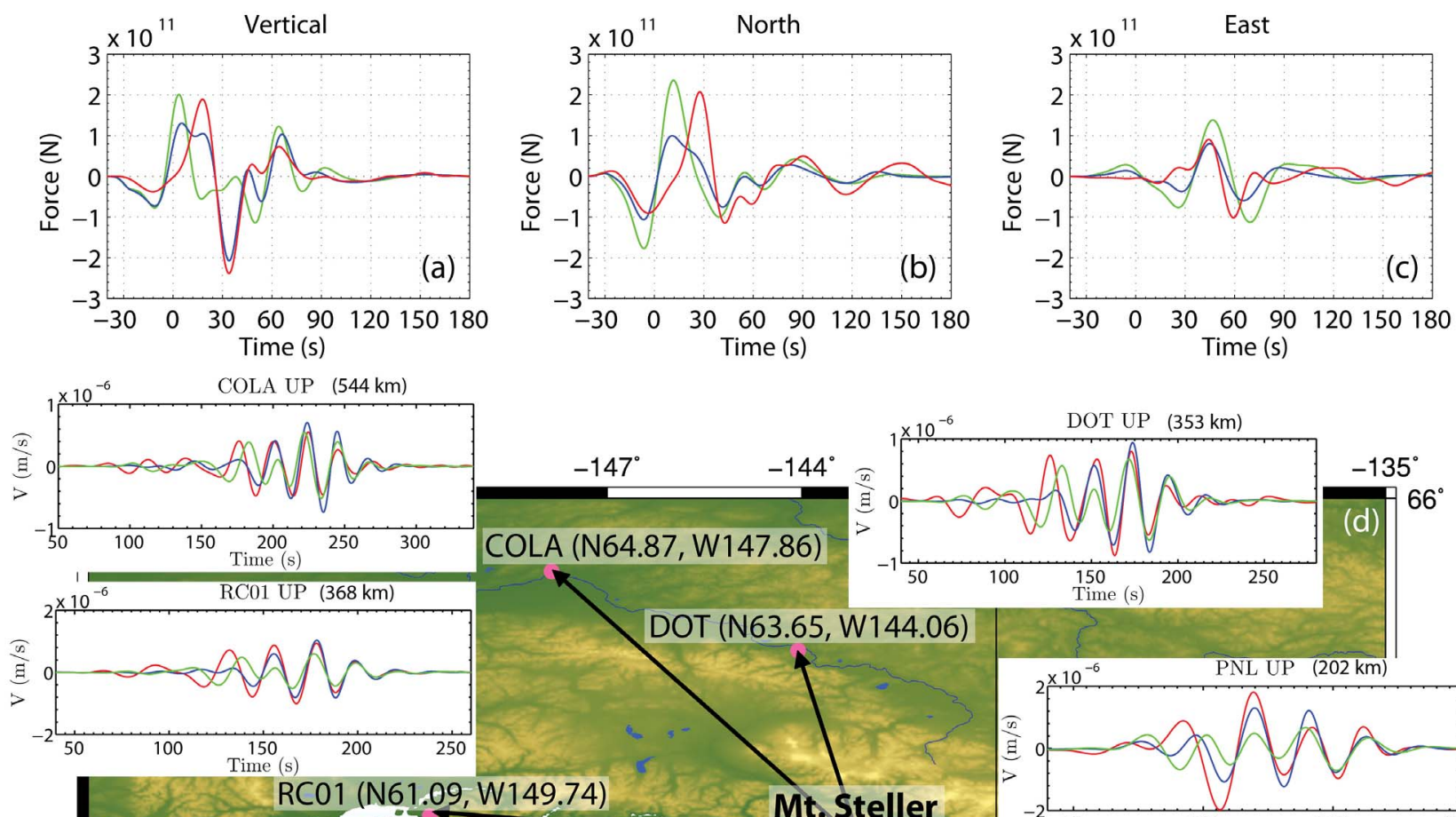

DOT (N63.65, W144.06)
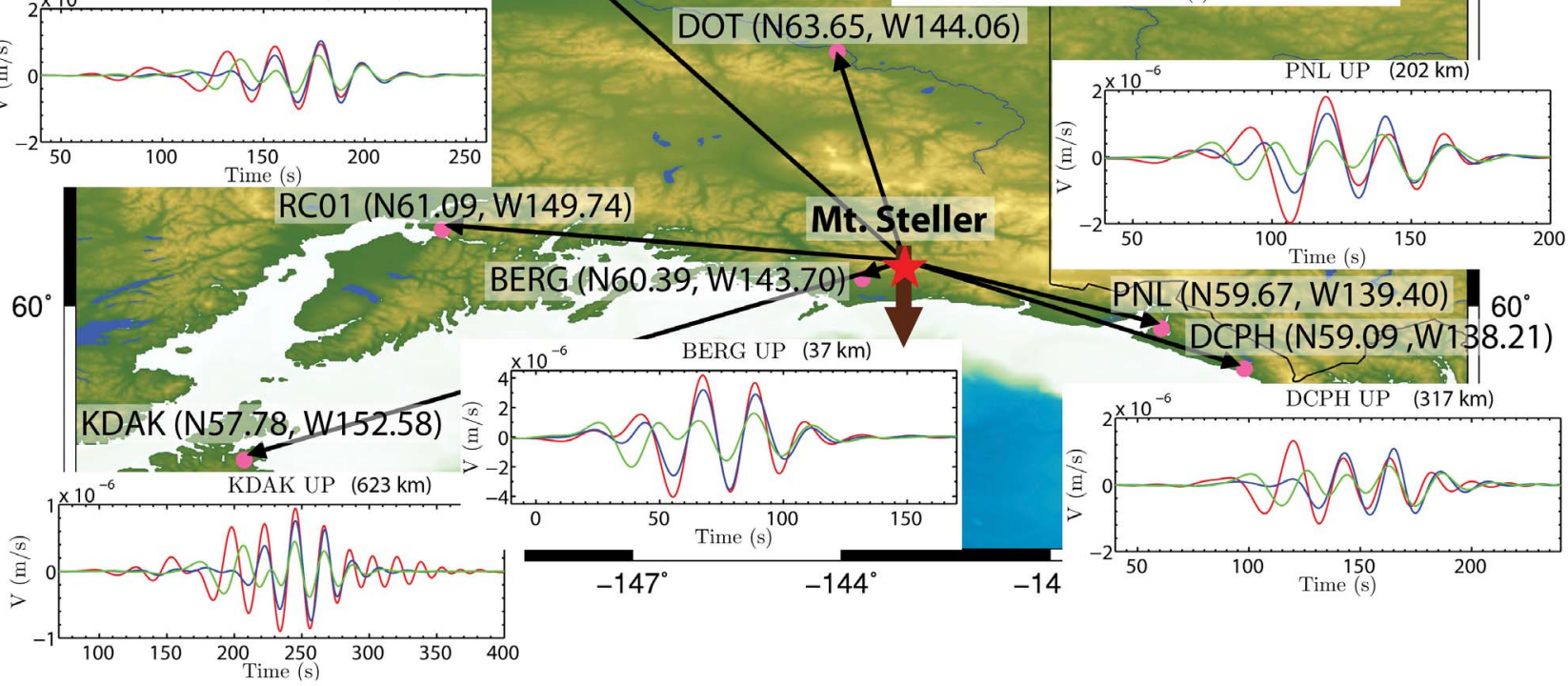

Figure 3. (a) Vertical, (b) north and (c) east components of the source functions, computed with the SHALTOP model for scenario 1 (green), scenario 2 (blue) and inverted (red). Source functions are filtered between 20 and 80 seconds. (d) The Mount Steller map with the simulated and recorded vertical component of the ground velocity filtered between 20-80 seconds. The red curve is from observed data while the blue and green curves are the simulated signal calculated respectively with and without taking into account erosion processes. The brown arrow indicates the flow direction of the landslide. The source-station distances are indicated beside the station names and the time shift values for each station with respect to BERG are, DOT: -12.5 s, PNL: -8 s, DCPH: -9 s, KDAK: $-12.3 \mathrm{~s}$, RC01: -10.5 s and COLA: $-15 \mathrm{~s}$.

generates excessively high energy seismic waves with no physical significance (e.g., at BERG the very first peak amplitude is increased by a factor of $\sim 4$ ), we did not take into account this first point of the source function in the wave simulations.

\section{Simulated and Observed Seismic Signals}

[19] The long-period (20-80 s) simulated and observed vertical components of the seismic signal are shown for each station (Figure 3d). Due to the simple earth model used here, arrival times are not reproduced exactly by the simulations and the signals have been shifted when they were not exactly in phase with the data. The time shift range $t_{s} \in[-15,0] \mathrm{s}$ is compatible with expected uncertainties in the rough and laterally homogeneous earth model used here (Figure 3).
Similar values of the shifts in this frequency range have been observed for an earthquake that occurred in the same region.

[20] Let us first focus on the closest station (BERG) at a distance of $37 \mathrm{~km}$. Scenario 2 (with erosion) very well reproduces the recorded seismic waves: the total duration and all the peaks of the recorded seismic signal are well reproduced, even though the amplitude is slightly underestimated. On the other hand, for scenario 1, only the signal duration matches the observations whereas the signal amplitude is underestimated by a factor of $\sim 2$ and the phase is incorrect. This can be understood by looking at the flow dynamics. Indeed, in the beginning, the larger mass released in scenario 1 generates a higher seismic signal. Later on, the main part of the mass stops upslope, leading to a smaller seismic signal than for scenario 2, for which almost the whole mass is still flowing up to the maximum distance 
reached by the avalanche (Figures $2 \mathrm{c}$ and $2 \mathrm{f}$ ). Changing the friction angles and the released volume in scenario 1 does not allows to reproduce the recorded seismic signal. Indeed, decreasing $\delta_{g 1}$ by $3^{\circ}$, increases the maximum amplitude by only $60 \%$ while $\delta_{r 1}$ has even smaller effect. On the other hand, an unrealistic volume of $160 \mathrm{Mm}^{3}$ has to be used to fit the maximum amplitude. Whatever these parameters, the wave form is always very different from the observation.

[21] The difference between the two scenarios is smaller at the other stations, all located at a distance of more than twice the maximum wavelength $(>200 \mathrm{~km})$. Nevertheless, taking erosion into account significantly improves the results at all the stations, making it possible to very well reproduce the end of the signal. For scenario 1 (without erosion), the amplitude is underestimated for most of the stations, especially regarding the second significant peak observed in the data (e.g., BERG at $t \simeq 70 \mathrm{~s}, \mathrm{PNL}$ at $t \simeq 120 \mathrm{~s}, \mathrm{RC} 01$ at $t \simeq 160 \mathrm{~s}$, or COLA at $t \simeq 200 \mathrm{~s}$ in Figure $3 \mathrm{~d}$ ). Whatever the scenario and for all the stations, the signal duration is well reproduced, except at KDAK station, possibly due to site effects. On other hand, the beginning of the signal is poorly reproduced in terms of amplitude and/or phase, except at BERG. The differences between simulated and recorded seismic signals may be due to the simple earth model used here.

[22] As a result, landslide dynamics are better reproduced when erosion processes are taken into account at stations with a large azimuth and distance coverage.

\section{Conclusion}

[23] We have simulated the rock-ice avalanche that occurred on Mount Steller in 2005, including the resulting source function and the generated long-period seismic waves, by combining a complex avalanche flow model and a wave propagation solver. We have made a first attempt to take into account erosion processes during the flow using a very simplified approach, shown to reproduce qualitative features of erosive granular flows.

[24] Comparison between observed and simulated seismic waves shows that taking into account erosion, even in this simplified way, makes it possible to accurately reproduce the long-period seismic signals (20-80 s) recorded at 7 broadband seismic stations that cover a wide range of sourcestation distances $(37-623 \mathrm{~km})$ and azimuths. On the other hand, when erosion processes are not taken into account, the resulting seismic signal does not match the observations. With this approach, we can constrain the friction coefficients used in the model, and this method would make it possible to constrain the volume of eroded material. In particular, taking into account erosion reduces the calibrated friction angles by about $7^{\circ}$.

[25] The key point of our approach is based on the fact that the stress applied on the topography by the landslide is highly sensitive to the flow history which itself depends on the rheological properties and physical processes during mass emplacement. As a result, the analysis of seismic signals generated by natural mass flows, continuously recorded by regional and global seismic networks, provides a unique diagnostic of these flows and therefore a way to validate flow models and gain quantitative insight into the physical processes at work.

[26] Further work is now required to investigate more natural landquakes and to introduce more realistic descriptions of key physical processes in the models such as erosion/deposition and the presence of a fluid phase.

[27] Acknowledgments. We thank Antoine Lucas, Clément Hibert, and Luis Rivera for fruitful discussions. This work was supported by ANR PLANETEROS, ANR LANDQUAKES, and CT3 INSU.

[28] The Editor thanks two anonymous reviewers for their assistance in evaluating this paper.

\section{References}

Bassin, C., G. Laske, and G. Masters (2000), The current limits of resolution for surface wave tomography in North America, Eos Trans. AGU, 81(48), Fall Meet. Suppl., Abstract F897.

Bouchon, M. (1981), A simple method to calculate Green's functions for elastic layered media, Bull. Seismol. Soc. Am., 71, 959-971.

Bouchut, F., and M. Westdickenberg (2004), Gravity driven shallow water models for arbitrary topography, Commun. Math. Sci., 2, 359-389.

Bouchut, F., A. Mangeney-Castelnau, B. Perthame, and J. P. Vilotte (2003), A new model of Saint-Venant and Savage-Hutter type for gravity driven shallow water flows, C. R. Acad. Sci., Ser. I, 336, 531-536.

Bouchut, F., E. Fernandez-Nieto, A. Mangeney, and P. Y. Lagre (2008), On new erosion models of Savage-Hutter type for avalanches, Acta Mech. 199(1-4), 198-208.

Brodsky, E. E., E. Gordeev, and H. Kanamori (2003), Landslide basal friction as measured by seismic waves, Geophys. Res. Lett., 30(24), 2236 , doi:10.1029/2003GL018485.

Dziewonski, A. M., and D. L. Anderson (1981), PREM is a 1D transversely isotropic, anelastic velocity and density reference model of Earth, Phys Earth Planet. Inter., 25, 297-356.

Farin, M., A. Mangeney, O. Roche, I. R. Ionescu, and O. Hungr (2011), Landslide boost from entrainment of erodible material along the slope, Abstract EP31E-0869 presented at 2011 Fall Meeting, AGU, San Francisco, Calif., 5-9 Dec.

Favreau, P., A. Mangeney, A. Lucas, G. Crosta, and F. Bouchut (2010), Numerical modeling of landquakes, Geophys. Res. Lett., 37, L15305, doi:10.1029/2010GL043512.

Hibert, C., A. Mangeney, G. Grandjean, and N. M. Shapiro (2011), Slope instabilities in Dolomieu crater, Réunion Island: From seismic signals to rockfall characteristics, J. Geophys. Res., 116, F04032, doi:10.1029/ 2011JF002038.

Huggel, C., J. Caplan-Auerbach, B. Molnia, and R. Wessels (2008), The 2005 Mt. Steller, Alaska, rock-ice avalanche: A large slope failure in cold permafrost, paper presented at Ninth International Conference on Permafrost, Univ. of Alaska Fairbanks, Fairbanks, 29 June to 3 July.

Iverson, R. M., M. E. Reid, M. Logan, R. G. LaHusen, J. W. Godt, and J. P. Griswold (2011), Positive feedback and momentum growth during debris-flow entrainment of wet bed sediment, Nat. Geosci., 4, 116-121, doi:10.1038/NGEO1040.

Jop, P., Y. Forterre, and O. Pouliquen (2006), A constitutive law for dense granular flows, Nature, 441, 727-730.

Kanamori, H., and J. W. Given (1982), Analysis of long-period seismic waves excited by the May 18, 1980, eruption of Mount St. Helens: A terrestrial monopole?, J. Geophys. Res., 87, 5422-5432.

Kawakatsu, H. (1989), Centroid single force inversion of seismic waves generated by landslides, J. Geophys. Res., 94(B9), 12,363-12,374.

Kuo, C. Y., Y. C. Tai, F. Bouchut, A. Mangeney, M. Pelanti, R. F. Chen, and K. J. Chang (2009), Simulation of Tsaoling landslide, Taiwan, based on Saint Venant equations over general topography, Eng. Geol., 104(3-4), $181-189$.

Legros, F. (2002), The mobility of longrunout landslides, Eng. Geol., 63, 301-331.

Lin, C.-H., H. Kumagai, M. Ando, and T.-C. Shin (2010), Detection of landslides and submarines slumps using broadband seismic networks, Geophys. Res. Lett., 37, L22309, doi:10.1029/2010GL044685.

Lucas, A., and A. Mangeney (2007), Mobility and topographic effects for large Valles Marineris landslides on Mars, Geophys. Res. Lett., 34, L10201, doi:10.1029/2007GL029835.

Lucas, A., A. Mangeney, D. Mège, and F. Bouchut (2011), Influence of the scar geometry on landslide dynamics and deposits: Application to Martian landslides, J. Geophys. Res., 116, E10001, doi:10.1029/2011JE003803.

Mangeney, A., L. S. Tsimring, D. Volfson, I. S. Aranson, and F. Bouchut (2007a), Avalanche mobility induced by the presence of an erodible bed and associated entrainment, Geophys. Res. Lett., 34, L22401, doi:10.1029/2007GL031348.

Mangeney, A., F. Bouchut, N. Thomas, J. P. Vilotte, and M. O. Bristeau (2007b), Numerical modeling of self-channeling granular flows and of their levee-channel deposits, J. Geophys. Res., 112, F02017, doi:10.1029/ 2006JF000469. 
Mangeney, A., O. Roche, O. Hungr, N. Mangold, G. Faccanoni, and A. Lucas (2010), Erosion and mobility in granular collapse over sloping beds, J. Geophys. Res., 115, F03040, doi:10.1029/2009JF001462.

Mangeney-Castelnau, A., F. Bouchut, J. P. Vilotte, E. Lajeunesse, A. Aubertin, and M. Pirulli (2005), On the use of Saint Venant equations to simulate the spreading of a granular mass, J. Geophys. Res., 110, B09103, doi:10.1029/2004JB003161.

Pouliquen, O., and Y. Forterre (2002), Friction law for dense granular flows: Application to the motion of a mass down a rough inclined plane, J. Fluid Mech., 453, 133-151. doi:10.1017/S0022112001006796.
Pudasaini, S. P., and K. Hutter (2007), Avalanche Dynamics: Dynamics of Rapid Flows of Dense Granular Avalanches, Springer, Berlin.

Schneider, D., P. Bartelt, J. Caplan-Auerbach, M. Christen, C. Huggel, and B. W. McArdell (2010), Insights into rock-ice avalanche dynamics by combined analysis of seismic recordings and a numerical avalanche model, J. Geophys. Res., 115, F04026, doi:10.1029/2010JF001734.

Ward, S. N., and S. Day (2006), Particulate kinematic simulations of debris avalanches: Interpretation of deposits and landslide seismic signals of Mount Saint Helens, 1980 May 18, Geophys. J. Int., 167, 991-1004. 